\title{
Intracerebral Haemorrhage with Choriocarcinoma in a Teenager - A Case Report
}

\author{
S DAS $^{\mathrm{a}}$, MM ISLAM $^{\mathrm{b}}$, MM RASHID $^{\mathrm{c}}$, MRA HOWLADER $^{\mathrm{d}}, \mathrm{S} \mathrm{DEY}^{\mathrm{e}}, \mathrm{H}^{\mathrm{N}}$ MAHBUB $^{\mathrm{f}}$
}

\begin{abstract}
Summary:
Intracerebral haemorrhage is one of the uncommon initial CNS manifestations of choriocarcinoma in reproductive age group women. Disease is usually diagnosed by history, clinical examinations and investigations like CT scan of brain and chest, MRI of brain, USG, X-ray chest $P / A$ view and high level of $\hat{a}-h C G$ in serum and CSF. Overall prognosis of this disease is generally good (80-90\% long term survival with chemotherapy and radiotherapy). But intracranial metastasis has poor prognosis which comprises 3-28\% of choriocarcinoma. Most intracranial metastasis occurs late in the course of disease but $20 \%$ experiences as first sign. Our patient is a teenager girl presented with convulsion and loss of consciousness. CT scan of brain
\end{abstract}

\section{Introduction:}

Choriocarcinoma is a gestational trophoblastic disease, is a highly malignant tumor arising from the chorionic epithelium, seen in young females and is associated commonly with molar pregnancy. About $3-5 \%$ of all patient with molar pregnancies develop choriocarcinoma, around $50 \%$ develop following hydatidiform mole, $30 \%$ after miscarriage or ectopic pregnancy and $20 \%$ after normal pregnancy. It is a rare gestational trophoblastic disease that complicates approximately 1 in 50,000 term pregnancies and 1 in 30 hydatidiform moles ${ }^{1}$. Among confirmed cases of

a. Dr. Sukriti Das, Associate professor, Department of Neurosurgery, Dhaka Medical College.

b. Dr. Md.Manirul Islam, IMO, Dept of Neurosurgery, DMCH.

c. Dr. Md. Mamunur Rashid, Resident Phase-B, Neurosurgery, DMC.

d. Dr. Md. Reaz Ahmed Howlader, MS Neurosurgery (Final Part Student), DMC.

e. Dr. Sharbori Dey, MBBS, FCPS, Consultant, BSSMU.

f. Dr. Hasan Mahbub, Resident Phase-B, Neurosurgery, DMC.

Address of Correspondence: Assoc. Prof. Dr. Sukriti Das, FCPS (surgery), MS (Neurosurgery), FRCS (Ed) Department of Neurosurgery, DMCH. Cell: 01711676848, Email: sukriti66@yahoo.com

Received: 8 November, 2017

Accepted: 15 December, 2018 revealed hemorrhage in right fronto-parietal region with ventricular extension, $X$-ray chest $P / A$ view shows metastasis in mid zone of right lung, USG shows invasion in posterior myometrium and high concentration of serum $\hat{a}-\boldsymbol{h C G}$ (273400 $\mathrm{mUI} / \mathrm{ml}$ ) confirmed our diagnosis. This case report describes that the conservative treatment with radiotherapy and chemotherapy gives good outcome of with metastasic intracerebral haemorrhage with choriocarcinoma is rewarding with farther radio and chemotherapy.

Key word: Choriocarcinoma, metastasis, invasion, Beta human chorionic gonadotropin (â-hCG).

(J Bangladesh Coll Phys Surg 2019; 37: 151-155)

DOI: https://doi.org/10.3329/jbcps.v37i3.41737

choriocarcinoma, $45 \%$ occur after molar pregnancy, $24 \%$ after normal term pregnancy, 25\% after spontaneous abortion, and 5\% after ectopic pregnancy ${ }^{2}$. Prognosis of this disease is generally good, 80-90\% long-term survival with chemotherapy, radiotherapy, and surgical excision in appropriate cases ${ }^{3}$. One of the indicators of a poor prognosis is intracranial metastases, which complicate between 3 and $28 \%$ of gestational choriocarcinoma. It usually disseminates haematogenously to the lungs, vagina, brain, kidney and ovaries with the obvious primary in the uterus. Most intracerebral metastasis occurs late in the course of the cancerous diseases ${ }^{4}$; however $20 \%$ of patient experience brain metastasis as the first sign of cancer ${ }^{5}$. Intracranial choriocarcinoma should be considered in any reproductive age female with evidence of cerebral metastasis. This case presented atypically as a case of severe headache, vomiting and repeated convulsion and finally unconsciousness following massive intracerebral haemorrhage with evidence of primary focus as invasive mole in the posterior myometrium (uterus).

\section{Case report:}

A 17 years old teenager girl, recently married was admitted in Neurosurgery department, Dhaka Medical 
College Hospital, as a case of intracerebral haemorrage in the right fronto-parietal region on NCCT (noncontrast computed tomography) of brain. She presented with the complaints of severe headache. Persistent bursting headache accompanied by nausea and vomiting for few hours with weakness in the left side, visual disturbance and finally developed repeated convulsion with loss of consciousness. There was no significant contributing family or past history but the obstetric history from attendant revealed that the patient was newly married on Jan 2017 and she developed menstrual irregularities with abnormal PV bleeding for which three times dilatation \& curettage was done and was diagnosed as a case of choriocarcinoma invading in the posterior myometrium confirmed by USG examination twice. A Magnetic Resonance Imaging (MRI) of brain and Magnetic Resonance Angiography (MRA) were done to locate the site of bleed. MRI of the brain showed huge left frontal haematoma with perilesional penumbra with normal MRA images . To rule out coagulopathies; prothrombin time (PT), activated partial thromboplastin time (APTT), serum anti nuclear antibody (ANA) levels were estimated and were found normal. Platelet count, peripheral blood film, detailed study of D-Dimer levels along with 2D Echocardiography and Utrasonography revealed invasion in the posterior wall of the uterus. But CXR

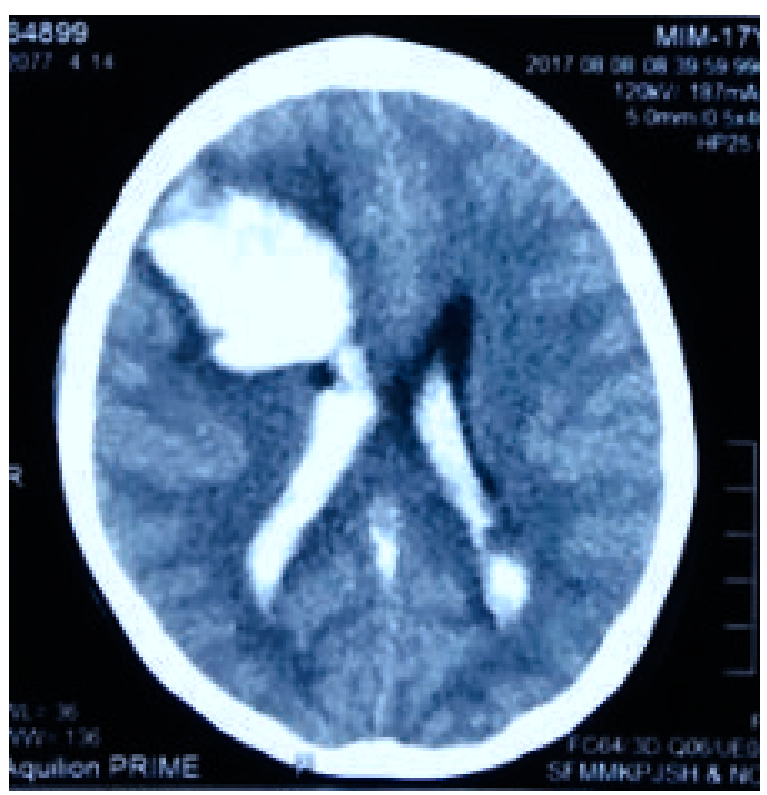

CT scan of brain on admission
$\mathrm{P} / \mathrm{A}$ revealed metastasis in mid zone of right lung. The fact that the patient had an early pregnancy loss and requiring dilatation and curettage repeatedly led us to estimate her serum Beta hCG level which was found elevated $87586.38 \mathrm{mIU} / \mathrm{ml}$ on $04.07 .2017,273400$ $\mathrm{mIU} / \mathrm{ml}$ on $08.07 .2017,260357 \mathrm{mIU} / \mathrm{ml}$ on 20.07.2017, $107883 \mathrm{mIU} / \mathrm{ml}$ on 09.08 .2017 and $31057 \mathrm{mIU} / \mathrm{ml}$ on 28.08.2017 which led to the suspicion of choriocarcinoma metastasizing to the brain. Normal Beta hCG level is $<5 \mathrm{mIU} / \mathrm{ml}$ in non pregnant women. Previously dilatation \& curettage was done and histopathological examination revealed choriocarcinoma / invasive mole. CSF examination showed WBC 8 cells/ cu mm, RBC $(+)$, Protein : 3 $\mathrm{gm} / 1$, glucose: $1.9 \mathrm{mmol} / \mathrm{l}$, and serum beta $\mathrm{hCG}$ $31057.20 \mathrm{mIU} / \mathrm{ml}$. The patient was treated conservatively by giving antibiotics, anticonvulsant, steroid, Mannitol and closely monitored her with high dependency unit (HDU) support. We planned radiotherapy and chemotherapy subsequently for this patient. Patient started improving gradually and now patient is alert, oriented and conscious GCS:15, no episode of convulsion any more in hospital. Now she is able to speak slowly, ambulate with assistant and has some focal motor deficit. Repeat NCCT of brain revealed size of the haematoma is regressing and is resolving. Patient was discharged with the advice of whole brain radiotherapy and chemotherapy.

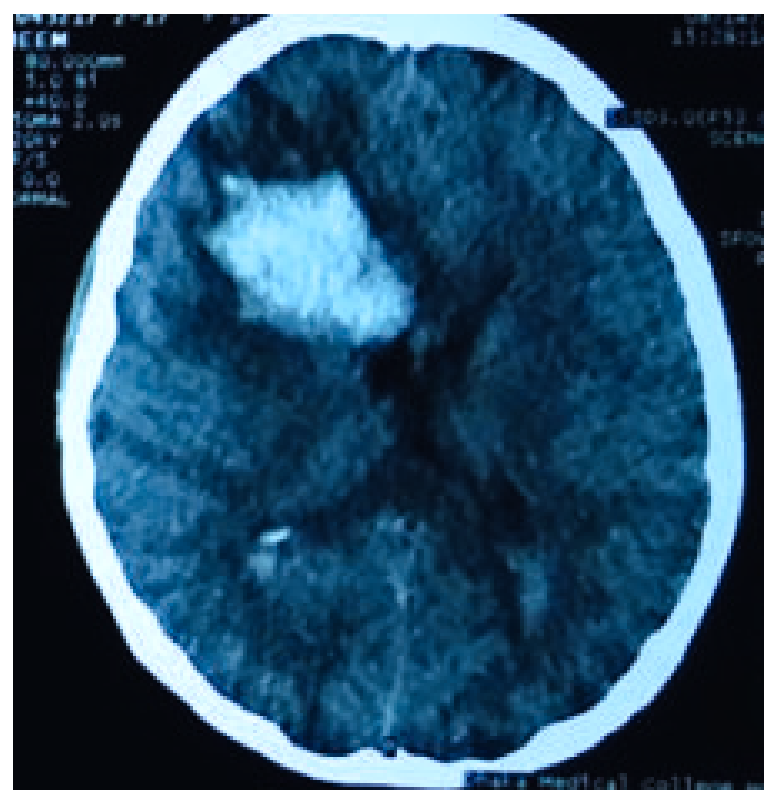

CT scan of brain on $5^{\text {th }}$ day 


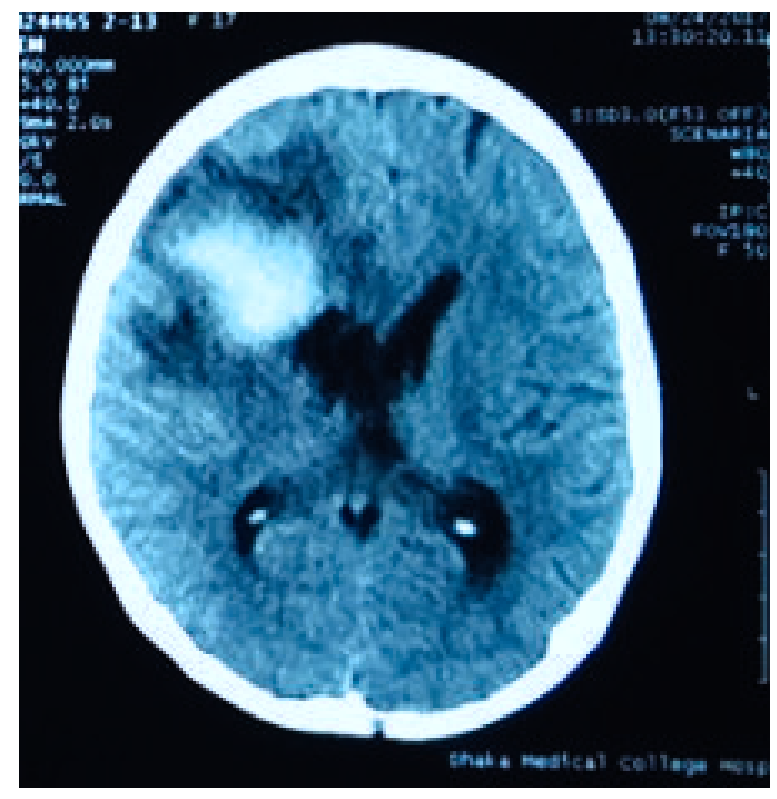

CT scan of brain on $12^{\text {th }}$ day

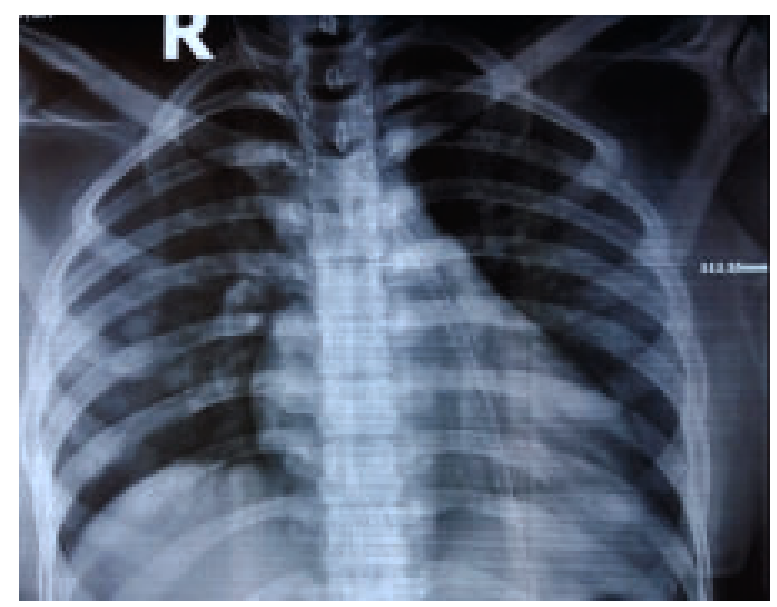

Chest $X$-ray $P / A$ view revealed metastasis in the mid zone of right lung.

\section{Discussion:}

Gestational trophoblastic disease was one of the first gynecological malignancies cured by chemotherapy and is the most curable of all female malignancies. Hydatidiform mole occurs in about 1 in 1000 pregnancies $^{6}$ and there is an increased risk in teenagers and women over 40 years ${ }^{7}$. About $2 \%$ to $3 \%$ of hydatidiform moles persist to choriocarcinoma. The incidence of choriocarcinoma is about 1 in 25,000 to $70,000 \cdot^{7,8}$

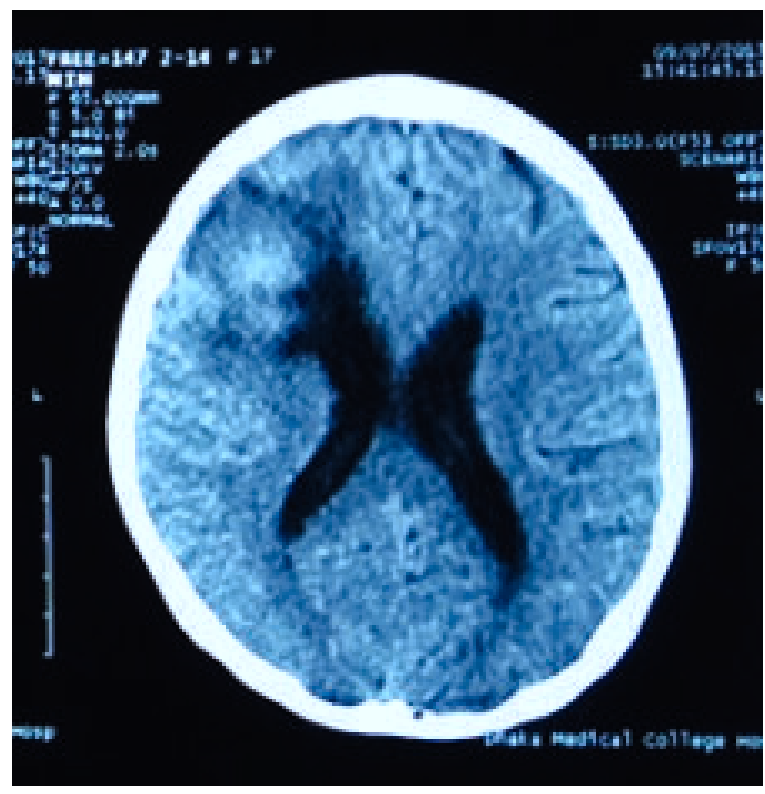

CT scan of brain on $19^{\text {th }}$ day

Gestational trophoblastic tumor are divided by Hammond et $\mathrm{al}^{9}$ used in most USA and Europe, into : nonmetaplastic, low risk metaplastic and high risk metaplastic group. Patient with nonmetaplastic, low risk metaplastic are virtually $100 \%$ curable but still some may die. High risk group patients are unlikely to be cured and usually treatment failure by single agent chemotherapy. Patients with one or two high-risks factors respond better than patients with three or more risk factors. Therefore, it is important to identify those individuals who are at high risk. Individuals with multiple high-risk factors are treated with multipleagents, with modifications, depending on liver or brain involvement.

A score of: 4 is considered low risk, 5 to 7 is considered moderate risk, and a score of $>8$ is considered high risk.

Choriocarcinomas are a malignant neoplastic form of the trophoblastic tissue with a tendency for early metastasis ${ }^{10}$. The tumour metastasises first to the lung and to the brain ${ }^{11}$. Cerebral metastasis occurs in 10 $20 \%$ patients with choriocarcinoma ${ }^{12}$.

Choriocarcinoma with cerebral metastasis have been associated with cerebral haematoma, arterial aneurysms, and embolic vascular occlusions ${ }^{13}$. The trapped neoplastic cells, in the form of emboli in the 
cerebral circulation, invade the vessel wall resulting in haemorrhage within the tumour or a partial disruption of the vessel wall that can lead to aneurysm formation and subsequent haemorrhage $[14,15]$. The most common cause of intra-cerebral haemorrhage is probably aneurysm rupture. Women with such cerebral metastasis may present with headaches, seizures, and gradually progressive deficits [16]. According to the prognostic scoring system by the WHO, our patient had a prognostic score of 8 , which is characterized as high-risk and predicts potential resistance to chemotherapy.

In the female patient of reproductive age, choriocarcinoma must be considered in the differential for any intracranial hemorrhage. A lesion may be apparent on CT scan, but often there is no lesion visible apart from the hemorrhage. Suresh reports a series of 10 hemorrhages from confirmed cases of choriocarcinoma in which only two had visible lesions on CT [17]. The key diagnostic feature, apart from clinical suspicion, is the elevation of beta-hCG in the serum and CSF. Elevated hCG in the serum of a patient with previous abnormal pregnancy strongly suggests choriocarcinoma or retained trophoblastic tissue. If the ratio of serum to CSF hCG is less than 60 , CNS metastasis is strongly suspected [18]. Presumably, if the decreased serum : CSF ratio is due to contamination with blood from hemorrhage, the ratio would normalize on serial studies.

Importantly, CNS metastases are very responsive to chemotherapy. There are reports of complete resolution of CNS disease including intracranial metastases, neoplastic pseudoaneurysms, and neoplastic fistulas with chemotherapy alone [19]. Given the good response of this disease to chemotherapy, in many cases, including resolution of CNS pathology, it is not necessary to perform surgical removal of asymptomatic lesions. Surgical treatment should be reserved for patients with symptomatic intracranial pathology that represents an immediate threat.

\section{Conclusion:}

We want to emphasis that metastatic choriocarcinoma should be considered as one of the differential diagnosis in women of child-bearing age with intracerebral haemorrhages (ICH) and earlier recognition may help in reducing morbidity and mortality due to the high rate of remission of choriocarcinoma, which makes it all the more important to diagnose and initiate treatment at a very early stage.

Increased beta $\mathrm{hCG}$ level can aid in the diagnosis and a low serum: CSF beta hCG level can be strongly suggestive of intracranial choriocarcinoma even in the absence of histologically proven disease.

The prognosis of patients with central nervous system metastasis from this type of tumor is excellent, despite any other metastasis. The hallmark of treatment is 3000 cGy of radiation to the cerebrum concomitantly with multiagent chemotherapy ${ }^{20}$. This treatment has resulted in survival rates of $70 \%$ to $89 \%$ in patients with brain metastasis ${ }^{21}$.

\section{References:}

1. Athanassiou A, Begent RH, Newlands ES, Parker D, Rustin GJ, Bagshawe KD: Central nervous system metastases of choriocarcinoma. 23 years' experience at Charing Cross Hospital. Cancer 1983, 52:1728-1735.

2. Redline RW, Abdul-Karim FW: Pathology of gestational trophoblastic disease. SeminOncol 1995, 22:96-108.

3. Kalafut M, Vinuela F, Saver JL, Martin N, Vespa P, Verity MA: Multiple cerebral pseudoaneurysms and hemorrhages: the expanding spectrum of metastatic cerebral choriocarcinoma. $\mathbf{J}$ Neuroimaging 1998, 8:44-47.

4. DelattreJY, Krol G, Thaler HT, PosnerJB. Distribution of brain metastasis. Arch Neurol 1988;45:741-744.

5. CairncrossJG, KimJH, PosnerJB. Radiation therapy for brain metastasis. Ann Neurol 1980;7:529-541.

6. Bracken MB, Brinton LA, Hayashi K. Epidemiology of hydatidiform mole and choriocarcinoma. Am J Epidemiot 1984;6:52-75.

7. Yen S, MacMahon B. Epidemiologic features of trophoblastic disease. AmJObstetGynecot 1968;101: 126-132.

8. Brinton LA, Bracken MB, Connelly RR. Choriocarcinoma incidence in the United States. AmjEpidemiot 1986;123:10941100 .

9. Hanmmond CB, Borchert LG, Tyray L, Creaseman WT, Parker RT. Treatment of metastatic trophoblastic disease: good and poor prognosis. AmJObstetGynecol 1973;115:4-10.

10. Baertschi E, Notter M, Mironov A et al. Cerebral Metastasis in choriocarcinoma, a case report (in German). Bern (1994) 2003; 92(16): 763-8.

11. Principles and Practices of Oncology. Vincent T. Devita Jr., Samuel Hellman, Steven A. Rosenberg (Eds.). 8th edition chapter 42, section 4, Pg - 1564 . 
12. Taiks, Chan FL, Ngan HY. Renal metastasis from choriocarcinoma:MRI appearance. Abdominal imaging 1998; 23: 536-8.

13. Adams and Victor's Principles of Neurology 9th Edition, Chapter $31, \operatorname{Pg} 632-3$.

14. Fujiwara T, Minos S, Nagao S, Ohomoto T. Metastatic choriocarcinoma with neoplastic aneurysms cured by aneurysm resection and chemotherapy. Case Report. J Nerosurg 1992; 76: 148-51.

15. Giannakopoulos G, Nair S, Snider C, Amenta PS. Implication for the pathogenesis of aneurysm formation: metastatic choriocarcinoma with spontaneous splenic rupture. Case Report and a Review. SurgNeurol 1992; 38: 236-40.

16. Berek and Novak's Gynaecology: Lipincott 2007 14th edition, Chapter 37, pg 1597.
17. Suresh TN, Santosh V, ShastryKolluri VR, Jayakumar PN, Yasha TC, Mahadevan A, Shankar SK: Intracranial haemorrhage resulting from unsuspected choriocarcinoma metastasis. Neurol India 2001, 49:231-236.

18. Bagshawe KD, Harland S: Immunodiagnosis and monitoring of gonadotrophin-producing metastases in the central nervous system. Cancer 1976, 38:112-118.

19. Gurwitt LJ, Long JM, Clark RE: Cerebral metastatic choriocarcinoma: a postpartum cause of "stroke". ObstetGynecol 1975, 45:583-588.

20. DuBeshter B, Berkowitz RS, Goldstein DP, Cramer DW, Bernstein MR Metastatic gestational trophoblastic disease: experience at the New England Trophoblastic Disease Center 1965-1985. ObstetGynecot 1987;69:390-394.

21. Yordan EL, Schlaerth J, Gaddis 0, Morrow CP. Radiation therapy and the management of gestational choriocarcinoma metastatic to the central nervous system. ObstetGynecol 1987; 69:627-630. 